Tünde Varga

\title{
Text and Interpretation Reconsidered
}

\author{
Intertextuality as the Being of Text: \\ Contrasting Gadamer and Paul de Man in the Light of Intertextuality
}

"Text and Interpretation" was a lecture delivered by Gadamer at a Paris conference in 1981. Derrida was one of the participants, and the following day he posed three questions to Gadamer in a short paper entitled "Guter Wille zur Macht." Derrida's contribution called forth a famous (or rather infamous) debate (a socalled encounter), which provoked many texts and much criticism on both sides.

Seemingly, there is no encounter between the two parties - between Deconstruction and Hermeneutics. The followers of the Hermeneutical school often blame Derrida, or the Deconstructive school in general, for not paying attention to their claims, or for their unwillingness to get involved in an encounter or dialogue (this seems an anathema in the eyes of hermenutists). Yet, although Gadamer sticks to the application of "good will" in the dialogical situation so as to facilitate understanding as the understanding of "the otherness of the other," Derrida suspects that on the whole "good will" is only an excuse for,

\footnotetext{
"I will rely on both the original German text and its English translation. "Text and Interpretation" in English can be found in Diane P. Michelfelder \& Richard E. Palmer eds. Dialogue and Deconstruction. Albany: State University of New York Press, 1989, pp. 20-51. Citations from the original German version will rely on the edition: Philippe Forget ed. Text und Interpretation. München: Wilhelm Fink Verlag, 1984, pp. 24-56. All parenthesised references are to these editions. In the use of terminology I also rely on this English translation of Gadamer's text; due to the problems of translating terms the English equivalents might seem misleading. I will reflect on a great many of these problem concepts, yet there might still occur some I have missed, which can cause disturbance in understanding, and for which I would like to apologise.
} 
or a disguise of the "Will to Power." Therefore, Derrida insists on reading along the "hermeneutics of suspicion" - to use Ricoeur's term - not only in the process of communication, but also in textual exegesis.

The common ground for both schools is their emphasis on the language bound nature of human understanding; Hermeneutics as well as Deconstruction deny the possibility of a transcendental ground that would govern understanding without the encounter of language. Thus, whatever knowledge is gained it is only possible by and through the means of language. Furthermore, due to its human origin language has its limits and boundaries in rendering either our knowledge (that is, epistemology) or our experience of subjectivity possible. The fundamental difference lies beyond the question of humanity's linguistic predicament: it is in how the two schools conceive this predicament in the act of "understanding" (or rather in the impossibility of it).

Gadamer conceives language as the medium of dialogue, as a fundamentally living predicament, which exists only in encounter. For Gadamer optimally every encounter aims at gaining a common plane - in his terms, at "the event of mutual understanding" -, which would be the meaning formed in the flow and exchange of the dialogue. ${ }^{2}$ In comparison Derrida sees language as incapable of reaching the "event" of understanding, since it always produces a textual excess that is outside the speakers' intention. Instead of considering language in living dialogue, he proceeds from the written sign predicated by a disruptive absence the absence of true or authentic meaning that lurks also in any ongoing dialogue. His concept of language culminates in the irreducible undecidability of meaning.

In "Text and Interpretation" Gadamer designates his project on the basis of the Heideggerian critique of subject so as to "conceive the original phenomenon of language in dialogue" (23). It would entail the reorientation of Hermeneutics toward "the art of the living dialogue" (23), and since, according to Gadamer, even Greek dialectics was aware of its "fundamental incompletability," his designated project does not aim at reaching "the ideal of the Absolute," the "ideality" of epistemology, unlike the project of positivist scientology. In opposition with the positivist inheritance, which presupposed the possibility to account exhaustively for experience by detailed scientific analysis, Gadamer wants to enlarge the project of Hermeneutics so as to take the experience of art and

\footnotetext{
${ }^{2}$ According to Gadamer "a word exists only in conversation and never exists there as an isolated word, but as the totality of a way of accounting by means of speaking and answering" ( $\mathrm{H}$. G. Gadamer. "Destruction and Deconstruction." Dialogue and Deconstruction, p. 112).
} 
history into account as well. He does it so because he bases the concept of understanding on Heideggerian grounds, that is fundamentally on the notion of what Heidegger called Dasein.

Dasein in Heideggerian philosophy is the cross-section of reality and probability, the way something can exist in the world in language through understanding. Therefore in order to apply the notion of Dasein Gadamer primarily seeks for the structure of Hermeneutics in art and history, in the world of the probable and not only in the world of scientific certainty. He assumes that the meaning of the work of art can never be fully grasped or accounted for by concepts, thus it leaves a residue of meaning that eludes the totalising project of scientific certainty.

The structure of Hermeneutics for Gadamer is also the structure of understanding; and this structure is that of circularity. The hermeneutical circle shows in Gadamer's words "the structure of Being-in-the-world [in-der-Welt-Sein] itself; that is toward overcoming of the subject-object bifurcation, which was the primary thrust of Heidegger's transcendental analysis of Dasein" (23). The notion of understanding and circularity thus jointed leads to the fundamental question of the factic - the question of 'Was ist Sein?' and 'Was meint es?' The answer to these questions can only be formed and reformed in (the circularity of) the dialogical situation, in "living dialogue." In opposition to the self-deceiving certainty of conceptual language, one's engagement in living dialogue can in no way result in absolute objective knowledge or meaning of the world, but in the permanent formation and re-formation of meaning between the participants of the dialogue.

Thus, in this sense, the anthropological aspect of language in conceiving and rendering meaning through words is paramount in Gadamer's Hermeneutics. Anthropological here could be conceived as the human aspect of mutual sense creation through or with the help of words that have no meaning or function outside the dialogue which provides their use, meaning, context, etc., the basic requirement for a sound interaction. The meaning of words formed this way are sound only within the boundaries of the interaction and only in that temporal situation, outside it - which also means their temporal displacement - they lose their agreed-upon sense and call forth renewed interpretation in the dialogical situation. This is how Gadamer aims at grasping the "inexhaustibility of the experience of meaning" (24). 
In his views what is can never be understood completely, since in Gadamer's own words "Being which can be understood is language," nonetheless, he goes on to claim that: "everything that goes under the name of language always refers beyond that which achieves the status of a proposition" (25). This exemplifies precisely the place of language and epistemology in Hermeneutics: there is nothing but language by which human epistemology is construed, by which knowledge can be achieved, but language can never achieve the complete and final meaning of things. Yet there is this obscure "beyond" that Gadamer eludes whenever he is blamed for being on the side of metaphysics. This "beyond" never ceases to return when he talks about the impossibility of closing the interpretative project, but claims the event of understanding to come about in the living dialogue.

Gadamer with the dialogical conception of language wants to exclude two things in the process of understanding. On the one hand the "the subjectivity of the subject" as his starting point in this process. It is because he claims for the hermeneutical circle or the circularity of understanding a certain "genuine universality," and this does not allow for ultimate subjectivity or the fallacious self-deceit of idealism (e.g. that of the Fichtean self-positing self) neither for the "self-certainty of self-consciousness." Moreover, the dialogical situation of the circularity of understanding requires a kind of "partner," even if it is only the inner voice of the soul as it is in the case of Socrates' daimon - no matter how much ideality this notion of the inner dialogue carries, if it is really to be conceived as genuine dialogue, which differs from, e.g., the ideality of the selfpositing self.

On the other hand, Gadamer wants to exclude interpretation to be viewed as a method. He claims that: "Interpretation is more than the technique of scientifically interpreting texts" (28). He considers language to be more than what fits into the category of "univocal notation," which was formerly believed achievable in philosophy (for instance the British empiricist tradition endeavoured to purify language from its tropes in order to reach the language of pure scientific

\footnotetext{
${ }^{3}$ The expression "beyond" is empathic in the clash of Deconstruction and Hermeneutics. Paul de Man picks it up in order to repudiate any plausibility of the transcendental, since as he states its only capability is to render the recurrence of the same. "Beyond," being the first part of the compound meta-phorein or trans-late - meaning carrying over to another realm (to transcend) - is never capable of carrying anything over or beyond what it posits. See Paul de Man. "Trope and Anthropomorphism in Lyric." The Rhetoric of Romanticism. New York: Columbia University Press, 1984.
} 
philosophy that would render objective and true knowledge of the world possible). The universal validity of natural sciences bases itself on a schematisation which is a rational construction, but which at the same time leaves out of sight the "midworld" of language [Zwischenwelt] (29). Nevertheless, the query of universality is not something Gadamer can easily do away with. In fact, although having repudiated the universality of scientific knowledge, he himself claims universality for Hermeneutics.

Dallmayr, in his paper, points at the contradiction of Gadamer's such statements as: "the universal claim of hermenutics is undeniable" and that the hermeneutical circle enjoys "true universality" on the one hand, and on the other hand that Gadamer talks about the "limits implicit in the hermeneutical experience of meaning." ${ }^{4}$ To put it differently: it is impossible to reconcile hermeneutics' claim to universality and its facing of limits within this universality. Unfortunately Dallmayr makes the mistake of seemingly equating understanding with "hermeneutical consciousness," in his words: "comments of this kind do not prevent Gadamer in the end from reaffirming the ineluctable primacy of understanding" or "hermeneutical consciousness."

In his letter to Dallmayr Gadamer defends himself with stating that there is difference between self-understanding [Selbstverständnis], self-consciousness [Selbstbewusstsein] and self-possession [Selbstbesitz]. This way, self-understanding which is not only possible through conversation with the other, but entails the "recognition of oneself in the other" as well - is probably of a higher order, or if not it is at least capable of avoiding the fallacy of logocentric or metaphysical certainty, since, in Gadamer's words: "it is an understanding that always places itself in question." 7

The chain that the 'being of language' is conceivable only in live conversation is what carries its universality, which, although impossible to prove, is supposed to be accepted within the tradition of Hermeneutics: "The fact that conversation takes place wherever, whenever and with whomever something comes to language - whether it is another person or a thing, a word, or a flame-

\footnotetext{
${ }^{4}$ See Fred Dallmayr. "Prelude. Hermeneutics and Deconstruction: Gadamer and Derrida in Dialogue." In: Dialogue and Deconstruction, pp. 84-85.

${ }^{5}$ Dallmayr, p. 85.

${ }^{6}$ H. G. Gadamer. "Letter to Dallmayr." In: Dialogue and Deconstruction, p. 95.

7 Gadamer. "Letter to Dallmayr," p. 95.
} 
signal (Gottfried Benn) - constitutes the universality of the hermeneutical experience." 8

In fact Gadamer is fairly categorical on the notion of shared or common experience, not only in this case, but - to recall another encounter - in his debate with Derrida. ${ }^{9}$ In Gadamer's "Letter to Dallmayr" it appears as the 'experience of understanding,' which is also in close relation to the experience of our limits in the dialogical situation, for not only understanding but also encountering limits is embedded in the dialogical situation. In fact understanding requires a "neverending dialogue," ${ }^{10}$ primarily because of the limits encountered. Gadamer here denies what Derrida blames him for, that is the possibility of rapport; to put it differently, the possibility of total mutual agreement in the event of understanding. Gadamer cannot accept this, since that would mean the closure of the supposedly never-ending dialogical situation, even if it were only a temporary one. In Gadamer's views the dialogue can never be stopped, for it would jeopardise the fundamental notion of hermeneutical understanding, that is the notion of "understanding-differently" [Andersverstehen]. He states that "where understanding takes place, there is not just an identity. Rather, to understand means that one is capable of stepping into the place of the other in order to say what one has there understood and what one has to say in response."11

Thus understanding, just like self-understanding, is a never-ending process: it is always in "play" as we are being played, and therefore neither the finality of self-consciousness, nor the closed nature of mutual agreement is acceptable within the framework of the play of the dialogical situation. Moreover, encountering limits, that one might call the disruption of the forgetfulness of language [Sprachvergessenheit], can confront one with the failure of understanding and thus designate the task of re-entering into the text or dialogue and, consequently, of getting involved in the interpretative process.

What manifests itself in the experience of encountering limits is once more the universality of the hermeneutical experience, to quote Gadamer: "The experience of limits that we encounter in our life with others - is it not this alone that conditions our experience and is presupposed in all the common interests bearing us along? Perhaps the experience of a text always includes all that binds us

\footnotetext{
${ }^{8}$ Gadamer. "Letter to Dallmayr," p. 95.

${ }^{9}$ H. G. Gadamer. "Reply to Jacques Derrida." In: Dialogue and Deconstruction, pp. 53-58.

${ }^{10}$ Gadamer. "Reply to Jacques Derrida," p. 57.

${ }^{11}$ Gadamer. "Letter to Dallmayr," p. 96.
} 
together." ${ }^{12}$ It is vital to emphasise that universality is not to be equalled with univocal, or final, it is better to be understood as the commonness of the communicative process in language. Gadamer rightly claims that entering into a dialogue - with someone else or with a work of art - does not necessarily lead to self-confirmation, neither to harmonious agreement. Yet he assumes that the work bears such a power that it "deals us a blow [Stoss]," ${ }^{13}$ which when accepted [er nimmt den Stoss an] then "the poetic text can so touch someone that one ends up 'entering' into it and recognising oneself in it" but at the same time "one must lose oneself in order to find oneself." 14

Let us suppose that it is not only about the power of the poetic work (which would lead to several problems: for instance in its most to that of essentialism, in its least to that of granting a somewhat privileged place to poetic language, which also draws attention to Gadamer's apparent oscillation about the nature of language in dialogue), ${ }^{15}$ but also about dialogue in general, then the "event" of understanding comes about when one finds oneself, that is when one recognises oneself in the "text." For the epistemological gain of bearing the possibility of selfrecognition - even if it is not something final that can be taken for granted - the loss of temporally losing oneself is a fair price to pay; thus the event of understanding is a positive experience, moreover for Gadamer it entails even more than sheer self-recognition. At this point however I find Derrida's criticism relevant, though a bit tongue in the cheek: "I am not convinced that we ever really do have this experience that Professor Gadamer describes, of knowing in a dialogue that one has been perfectly understood or experiencing the success of confirmation." ${ }^{16}$ And clearly, how does one have the certainty if understanding is always understandingdifferently, if it cannot be brought to a halt at any moment in the living dialogue?

There are several concepts that have occurred so far which need to be defined or at least accounted for. This is the task which comprises the project of this paper, as they are all closely related. These concepts are the following: the concept of text, interpretation, language and dialogue, play and the ideality of the art-work.

\footnotetext{
${ }^{12}$ Gadamer. "Reply to Jacques Derrida," p. 57.

${ }^{13}$ Gadamer. "Reply to Jacques Derrida," p. 57.

${ }^{14}$ Gadamer. "Reply to Jacques Derrida," p. 57.

${ }^{15}$ It is because the most crucial claims are always about the interpretative dialogue with the work of art which, nevertheless, bears - just to give one example - the "celestial' power to deliver a "thrust" upon its readers.

${ }^{16}$ Jacques Derrida. "Three questions to Hans-Georg Gadamer." In: Dialogue and Deconstruction, p. 54 .
} 


\section{ON THE NOTION OF TEXT}

Firstly, I will attempt to elucidate the concept of text starting out from "Text and Interpretation." Gadamer notes as a preliminary remark that "only on the basis of the concept of interpretation does the concept of the text come to constitute a central concept in the structure of linguisticality; indeed what characterises the concept of text is that it presents itself only in connection with interpretation and from the point of view of interpretation" (30). Accordingly, the notion of text and the notion of interpretation are so closely intertwined in this view that it is almost impossible to separate them. Nevertheless, Gadamer goes on to claim that "it is often interpretation that first leads to the critical restoration [Herstellung] of the text" (31). Thus interpretation is not something that is inseparable from the text, but it is responsible for the existence of the text in the first place. This defines that the text as a hermeneutical notion must be conceived as an intermediate product [Zwischenprodukt] and not as an end product as it is viewed from the perspective of grammar and linguistics (this is really the repudiation of Deconstruction as well). Since the intermediate product called text is formed in the midworld [Zwischenwelt] of the system of language, it is neither bound to conceptual finiteness.

What is at issue here for Gadamer is "the enigmatic nexus between thinking and speaking" (29), since in opposition with the symbolism of mathematical language - which is supposed to express "reality in propositional statements" (29), and from which the midworld of language is left out - he underscores "the primary mediateness of all access to the world [...] the inavoidability of the linguistic schema of the world" and "the priority of the domain of language" (29) by which "the midworld of language has proven itself to be the true dimension of that which is given" (29, emphasis mine). The claim of being enclosed or imprisoned in language is well-known in post-structuralist theory, nevertheless the emphasis on the midworld of language has its importance, inasmuch as the text - as intermediate product - is called forth in this world unseparably from interpretation. On the one hand, interpretation is what "performs the never fully complete mediation between man and world, (and to this extent the fact that we understand something as something [etwas als etwas] is the sole actual immediacy and givenness)" (30), on the other hand, according to Gadamer, "the so-called 'given' cannot be separated from interpretation" (30).

Gadamer's remarks on the nature of text, however, are not entirely devoid of contradiction. I hardly find reconcilable statements like: "In this 
manner it becomes a 'text'; for that which is said is not simply understood, rather it becomes an object" (32), though elsewhere he states that "we must say that a text is not simply a given object but a phase in the execution of the communicative event [Verständigungsgeschehen]" (35). Furthermore, the notion of phase also comes up earlier in connection with understanding: Gadamer claims that text as intermediate product is a "phase in the event of understanding that, as such, certainly includes a definite abstraction, namely, the isolation and reification [Fixierung] involved ${ }^{17}$ in this very phase" (31).

The reified or fixed form of the event of understanding, as the form of the "object" of the text, definitely contradicts Gadamer's notion of understandingdifferently. It is no wonder that he, at the same time, denies that the text is a given object, otherwise it would not be possible to maintain the idea that the text is an intermediate product, which is formed or created in the - dialogical - process of interpretation. If he allowed for the temporal fixation of form when the event of understanding takes place in us, then he would be very close to the deconstructive claim that meaning is only a superimposition on the text, which freezes momentarily the play or différance of it into an ideological construct.

Text for Gadamer then, it seems, is the product of interpretation and therefore the two are inseparable, yet it does not provide much information to circumscribe these two terms. All the same, since Gadamer every now and then reaffirms that the text can also be conceived as the "wording [Wortlaut] of the text" (33) to which one can return when understanding fails, or elsewhere: it is possible "to refer back to the signs and writing [Zeichenbestand?" (33) in case of failure.

It is clear that Gadamer wants to repudiate the structuralist-linguistic method of focusing only on "the punctuation and symbolisation [Zeichensetzung und Zeichengebung] that occur" (31) in a text in order to give an account of that text, but it turns out to be impossible to leave out of consideration the "Zeichenbestand" that constitutes the text. He states that "every return to the 'text' [...] refers to that which was originally announced or pronounced and that should be maintained as constituting a meaningful identity" (35). Although the

\footnotetext{
17 The English word "involved" might cause a problem here; it is actually missing from the German original: "eine Phase im Verständigungsgeschehen, die als solche gewiß auch eine bestimme Abstraktion einschließt, nämlich die Isolierung und Fixierung eben dieser Phase" (Forget, p. 341). This means that it is the isolation of the phase that happens and not that this phase involves an isolation.
} 
word "Urkunde" is missing from the English translation it is still clear that the idea of some sort of a 'fixed text' is maintained, which underlies what is announced, that is the "Kunde," which the "Urkunde-Kunde" relationship as probable wordplay conveys. The fact that he wants to keep in play the wording of the text, as well as the notion of its dialogical creation [Herstellung], in the interpretative process, causes difficulties in conceiving what is really meant by "text."

\section{ON THE NOTION OF INTERPRETATION}

At this point it will probably be more fruitful to turn to the notion of interpretation. First, the word's etymology: according to the Oxford English Dictionary ${ }^{18}$ 'to interpret' means to expound the meaning of something abstruse or mysterious; to render (words, writings, an author, etc.) clear or explicit; to elucidate; to explain. The word, nevertheless, goes back to a Latin origin, interpretari, that is, to expound, explain, translate, understand and, in the passive sense, to be explained; in Latin rhetoric the word meant the use of synonyms, the explanation of one word by another. The Latin verb was formed on interpres: an agent, an explainer, expounder as well as translator, and also carries in its prefix "inter" the notion of between, the state of being an intermediary, a go-between. In fact Gadamer makes use of the notion of interpretation in the above mentioned senses.

Interpretation is to be viewed as a kind of translation of the text, which is required when some sort of a disturbance is experienced in the process of understanding. Otherwise the forgetfulness of language, in which the text is encased, blocks us from being confronted with our non-understanding, from the tendency to reiterate meaning instead of its re-creation in the interaction with the text. In Gadamer's words: "Only when the process of understanding is disrupted, that is, where understanding will not succeed, are questions asked about the wording of a text, and only then can the reconstruction [Erstellung] of the text become a task in its own right" (32). Also, elsewhere he writes: "One can almost say that if one needs to reach back to the wording of the text, that is, to the text as

${ }^{18}$ J.A. Simpson \& E.S.C. Weiner eds. The Oxford English Dictionary. Oxford: Clarendon Press, 1989 (2nd edition), Vol. VII, pp. 1131-1132. 
such, then this must always be motivated by something unusual having arisen in the situation of understanding" (33, emphasis mine).

The situation of writing, nevertheless, differs from the situation of the "immediacy of conversation," this is so, because in conversation, that is, in the specific situation of communication [Verständigungssituation], there is place to avoid misunderstanding by the "obvious correction resident within living conversation" (34). Yet, although it is impossible to provide place for constant correction in writing, there still must be place for the possibility of conversation, and this conversation must also "look forwarh." So "all that is said is always already directed toward understanding [Verständigung] and includes the other in itself" (34), that is, toward the othe; of the dialogue which supposedly coincides with the reader. The written (or printed) text has to be such that "a 'virtual' horizon of interpretation and understanding must be opened in writing the text itself, one that the reader must fill cut" (34).

The task of the inrerpretation and that of the interpreter lies precisely in this opening up the text, namely, to "achieve such an understanding and to let [and to make] the text speak again [den fixierten Text wieder sprecisen zu lassenf, (35). Whenever the understanding fails interpretation has to re-start again and fold back on the text, re-enter the text, thus opening up its horizon every now and then and make its sense communicate to us through "Verständnis" (that is

\footnotetext{
${ }^{19}$ There are three curiosities in the English translation which entail serious philosophical problens, First, the English translation uses the expression of "printed text," whereas in the Gerrasu original "schriftiche Fixierung" can be found. Yet, the diference of writien and printed text is riore intricate a problem. Therc are several authors who diswss the problem brought about by the appearance of print. See Walter I. Ong. Orality and Iitcracy. London: Methuen, 1982; Eric Havelock. The Muse Learns to Write: Reflections on Oratity and Literacy from Antiquity to the Prevert. Nerv Haven and London, 1986. Guilielmo Cavalio \& Roger Chartier. Historie de la lociare dans le monde occkienial. Paris: Editions du Jeuil, 19\%7. Secondly, and this is more decisive here, the word "virtual," which is entirely missing from the Germat original: "dals sei den anderen erzeimen, so muß beim Schreiben, das kein Suchen und Finden die Worte mitteilen kann, qleicisam ein Auslesungs- und Verständrishorizont im Text selbst geöffnet werden, den der Leser auszufüllen hat" (Forge, p. 344). The expression "virttal" alreacy carrics a havy buiden of interpretative fixation en the part of the translator in considering he notion of the "horizon of interpretation and understanding." I doubi that Gadaner himself would agree of its being only "virtual," whatever the translator had in mind by using this word. Jast, to use "understanding" when oniginally "Verständigung" is used might be lightiy misleading, siace it is precisely the surplus involved in "Verstündigurg" what counts in tice concept of understanding in Fermeneatics, namely, the coming to a common plane through agrement and thus forming tie meaning of something in the event of uncierstanding. "Verständigung" means not only understanding, but making somebody understood.
} 
understanding in common agreement). This opening up is also the depository of readability: in order to avoid unreadability of the text one must always "look ahead to an understanding of that which is said in the text" (32). As opposed to considering the text as a mere system of signs, one has to count with the meaning of it, with what is said: "For in every case, whether of a spoken or written text, the understanding of the text remains dependent upon communicative conditions that, as such, reach beyond the merely codified meaning-content of what is said" (33). Therefore understanding is conditioned by, and dependent on the "good will" of the partners in this communication.

The spoken nature of what is said has crucial importance from the aspect of Gadamer's ultimate aim: $\mathrm{He}$ is to prove that the literary art-work bears its "own authenticity" in itself because "in literature we find that language itself comes to appearance [zur Erscheinung] in a very special way" (42). The notion of communication, and corollary, speech [Rede] - put in the foreground - bear importance because Gadamer, in the final analysis, tries to prove plausible that the art-work can speak or communicate itself to us without the mediating function of the interpreter. The art-work "itself has its own value" (51), which shines in its appearance [scheinen-Erscheinung] without any necessary translation: "the literary text is not interrupted by the dialogical and intermediary speaking of the interpreter" (46). Due to its own value, the literary text can speak to us if there is the "readiness" (or good will one might say) in us "to be 'all ears' lganz Ohr zu seinf" (49), and since the ambition of the literary work is not to convey a message, but "to become present in its linguistic appearance [...] it must not only be read, it must also be listened to - even if only mostly with our inner ear" (43). This way "the interpreter, who gives his reasons, disappears - and the text speaks" (51). This is what Gadamer calls the "eminent" text and which is qualified as a text capable of "fulfill[ing] its authentic being [Bestimmung] as text [...] in textual forms" (37). Furthermore, literature is a text "in the highest degree," so much so that "it seems to originate in itself" $(42) .^{20}$

\footnotetext{
${ }^{20}$ There are several other statements in Gadamer's paper that reaffirm this metaphysical dignity or height of literary text, e.g. "[a] literary text possesses its own status" (44); "it is in the literary text that the word attains its full self-presence [Selbstpräsenz]" (43); "the fullness of meaning first emerge in its total volume" (44). Or in connection with the definition of the eminent text: "Every part of speech, every member, every individual word that submits to the unity of meaning in the sentence, represents in itself also a kind of unity of meaning insofar as through its meaning something meant is evoked" (43). The metaphysic nature of conceiving literature this way resides in two things: on the one hand, these definitions of the literary presuppose some kind of an intellect which would be able
} 
Interpretation has a very special role in connection with this notion of literature, which differs from the interpretation of ordinary text or even from texts that cause "distorted intelligibility," since they "offer resistance and opposition to textualization" (37). Whereas interpretation is normally required in case of non-understanding or disturbed understanding, when it comes to literature interpretation cannot be left aside; it is the ineluctable "part" of the text, in fact it is constitutive part of the text in its ubiquity. Interpretation in literature is not to be conceived as the "mediating discourse of the interpreter" [Dazwischenrede], since its primary function does not lie in its function of translation, but it is to be viewed as "the interpreter's constant co-speaking" (46). Co-speaking is what designates the structure of literary interpretation and understanding as a circular one, and not as the traditional notion of a successive, temporal unfolding. It resembles reading aloud, the process in which "the reader belongs to the text," and which "remains "dialogical" (or that of reciting) that is, it is "not merely arranging a series of fragments of meaning one after the other," but "will render a linguistic gestalt fully present" (47). In the act of interpretation as co-speaking, understanding occurs as a "sudden reversal that comes like a blow from without" and thus the "disordered fragments of the sentence, the words suddenly crystallise into the unity of a meaning of the whole sentence" (48).

to recognise these signs that show literature to be literature. Nonetheless, I wonder, just to give one example, who would possibly be so brave as to state whether or not there are superfluous words in a text, not to repeat Derrida's doubt about the event of understanding happening to us. On the other hand, and I recognise this might be a heavier claim, if there is no presupposed intellect involved in the designation of the margins or borders of literature, then to the extent that literature is meant to be "texts that do not disappear in our act of understanding them but stand there confronting our understanding with normative claims and which continually stand before every new way the text can speak" (41) - its borders are self-contained and therefore fall outside of any human control or revision. It means that Gadamer conceives literature to be able to justify itself as literature and the borders between the literary and the non-literary are completely independent of human design or intention. By 'intention' I mean the aspects by which a certain canon is designated. Does Gadamer really think that canons are in force devoid of any policy purely because of their utmost literary value? And if he does so then what explains the re-formation of canons by the change of perspectives? Of course the dialogical situation through which one allows himself to enter the text and through which one receives "a sudden instant of understanding $[\ldots]$ in which the unity of the whole formulation is illuminuted" (48) involves human presence to justify that literature is literature; but is it really comprehensible as human, is it still within our control or comprehension? 
The notion of sudden reversal with its ineluctable transformative power comes up at several points in Gadamer's oeuvre. In Truth and Method ${ }^{21}$ it occurs in connection with the concept of play at several places, but this notion can also be traced in the "The Ontological Valence of the Picture." Play, according to Gadamer, is the "mode of being of the art-work," it "fulfils its 'purpose' only if the player loses himself in the play," thus it cannot be considered entirely subjective but carries a certain "ideality" in itself which is revealed by the change the subject experiences in the transformative power of the play. In Gadamer's words:

the work of art has its true being in the fact that it becomes an experience that changes the person who experiences it. The 'subject' of the experience of art, that which remains and endures, is not the subjectivity of the person who experiences it, but the work itself. This is the point at which the mode of being of play becomes significant. For play has its own essence, independent of the consciousness of those who play. ${ }^{22}$

This play, then, in order to achieve its ideality, casts a transformation on the players involved, who lose themselves in the play while they are being played at the same time ("all playing is being played" 23 ), so that they can experience the effect of the art-work, which in turn attains "genuine completion": "I call this change, in which human play comes to its true consumation in being art. Transformation into structure and total mediation [Gebilde); only through this change does play acquire ideality, so that it can be intended and understood as play."

The "Gebilde" of the literary work manifests itself in the unity of understanding and meaning, but with the restriction that "something else speaks in the literary text that makes present the changing relationship of sound and meaning" (49). That is, the co-speaking [Mitrede], which constitutes the literary text, and which renders the "whiling" with the text [Verrveilen, tarrying, lingering] possible, thus manifests its circular structure in time. ${ }^{25}$

${ }^{21}$ Hans Georg Gadamer. Truth and Method. Translated by Joel Weinschümer and D.G. Marshall. London: Sheed and Ward, 1993.

${ }^{22}$ Gadamer. Truth and Method, p. 102.

${ }^{23}$ Gadamer. Truth and Method, p. 106.

${ }^{24}$ Gadamer. Truth and Method, p. 106.

${ }^{25}$ I cannot agree with Dallmayr in his view that interpretation is what is superimposed over the play of aesthetics and thus "integrated in, and subordinated to, a quasi-idealist hermeneutics of understanding and self-consciousness" (Dallmayr, p. 80). He claims that as a result of this the text in 


\section{TEXTS THAT FALL OUTSIDE THE LITERARY(?)}

Interpretation in the realm of literature, as we have seen, is a special case for Gadamer, it is no wonder he wants to differentiate as well as to disclose some types of texts with the interpretative approach applied to them. First, there are texts, called "consumption" or "use text" which disappear in the act of interpretation with the event of understanding. The interpretation of these texts is what Gadamer calls "Dazwischenrede" as opposed to the "Mitrede" of the literary. Although nothing specific is indicated about the possible recognition of these texts, they presumably gain their property from a lack, that is, these texts which, unlike the literary ones, dissolve in understanding. In Gadamer's words: with "the process of understanding a text tends to captivate and take the reader up into that which the text says, and in this fusion the text drops away" (41), whereas, as it has been already mentioned the literary text does not disappear but "stand[s] there confronting our understanding with normative claims" (41). Literary texts arc "only authentically there when they come back into themselves" ${ }^{26}(41)$, but it is not true for "ordinary" ones, since to return to the "ordinary" text and to restart the act of interpretation is required only when there is a disturbance in the decoding, when the understanding is disrupted. When this disruption is overcome the text becomes intelligible again and there is no more need for the "Dazwischenrede" of interpretation, thus the incomprehensible part of the text dissolves in the explanation, that is, in the event of "fusion of horizons [Horizontverschmelzung]." As for "use texts" the function of interpretation is fairly clear-cut, but it makes a stark contrast with the literary: since in the literary the "Mitrede" of interpretation does nor dissolve at any point, as does "Dazwischenrede" in the use text.

\footnotetext{
its understanding is thrust into the ontological reformulation of aesthetics, since interpretation is Hways already inscribed in the text, it is the part of the text or the meaning and understanding of it. Yet, he is right in that the sudden reversal, in which the play or art-work attains its ideality as "Gebilde" carries this burden of ontological self-affirmation. Therefore it threatens with the possibility that understanding will bring forth a momentary halt in its supposedly ongoing process at the very moment when its event does happen.

26 The English translation at this part of the iext is an interpretation suggesting more than the German original, which claims that the text is text only in and by itself without the reader or interpreter, that is what we could cbserve in connection with "play" in which the subjectivity of th: player dissoives, he is being piayed. Here interpretation, interpreter and text are merged into eacis ther without any possibility to separate them.
} 
The question, nevertheless, might arise that if interpretation is a "Mitrede," that is, the constant folding or turning back to the text, then how can the event of understanding happen? How is it possible to be certain at any stage text whose meaning production is interpretation related, that understanding really happens, if the turning back to the text can never be stopped, in other words, when understanding is disrupted at all points? Yet, if the event of understanding cannot be stated with full certainty and corollary the "Gebilde" is threatened, then it opens a gap for the possibility of multi-voicedness. In order to avoid the multivoicedness of the text to the extent which would disfigure or deface its intelligibility, Gadamer tries his best through stating that: "In cases of conflict [bei Anstößen] the larger context should decide the issue" (51) as the principle of Hermeneutics. What "larger context" is supposed to be if the text is probably disrupted at every point or if the interpretative process is in the act of constant "Mitrede" - which forms dialogically any sense whatsoever -, is difficult to see.

I presume Derrida's query about designating the border of context can be related to this point as well. But what casts a heavier weight on the question, is the problem of designating this so called "larger context" in opposition to the other possibilities of understanding or in the "possibility of double understanding," which Gadamer tellingly derides as "an offence [Ansto $\beta$ ?" (50). He also mentions that in the richness of literary texts there is place for other possibilities of meaning but only when - to put it somewhat crudely - kept under control. In Gadamer's words: "In a literary text, the accompanying meanings that go along with a main meaning are certainly what give the language its literary volume, but they are able to do this by virtue of the fact that they are subordinated to the unity of meaning of the discourse and the other meanings are only suggested" (45). He makes this claim in connection with "play on words" [Wortspiel], to which I intend to return later on. Here its interest lies in the fact that although Gadamer clings to the priority of "main meaning" or "larger context" - which, if we keep his theory under the necessary rigours he insists on, is not possible without the formative agreement of the interpretative reading - he admits the existence of other threads for forming understanding, with the restriction that it can occur only in the form of "accompanying meaning."

Yet, this way of viewing the proliferation of meaning does not remove its dangers for, as Gadamer goes on, it bears the power that "shatters the unity of discourse and demands to be understood in a higher relation of reflective meanings" (45). If it is so, then it would be a serious threat to Gadamer's claim on 
the unity of understanding, that is, in Gadamer's words that there is "a sudden instant of understanding here in which the unity of the whole formulation is illuminated" (48). This way only understanding as understanding-differently can be kept, however, then in turn, the idea of "main meaning" is thrown into doubt. These ideas nonetheless deal with the realm of the literary only, which, in many respects, is the most intricate field of the notion of textuality. Therefore, it would make some of the issue of interpretation and understanding more controversial, if we went on with the elucidation of Gadamer's notion of texts outside the realm of literature.

All the main exclusions Gadamer makes in order to save his idea of the unique, self-evident literary text are closely related to this issue of the possible multi-voicedness or to the ambiguity of text (except for two other types which are related to the above mentioned "ordinary or use text"). "Ordinary texts," as I have already noticed, disappear with the explanatory "Dazwischenrede" of the interpretation. One typical case of this occurrence is when one is reading back one's notes. But the most typical is when a special disruption of understanding makes the return necessary, which frequently happens in connection with scientific texts, they are special cases, since "scientific communication [ ] presupposes definite conditions of understanding from the outset" (33). ${ }^{27}$

It suggests that there cannot be any problem in the act of deciphering the text as long as the argument follows the plausible route that was previously designated within the boundaries of the given science. Only when the possibility of reiteration dissolves, when the pre-set conditions and boundaries fail to fulfil their task, will the reader return to the text in order to apply the process of interpretation, posing the question "whether or not there is a misunderstanding somewhere"(33). Thus, in connection with scientific communication Gadamer does acknowledge the existence of understanding by ways of formalisation (its likeliness to mathematical computation) that in turn involves the possibility of reiteration.

Now the whole query of the exception of science reverts in Paul de Man's study on Kleist in quite a curious context from our present point of view:

\footnotetext{
27 The German original is: "Das ist etwa die wissenschaftliche Mitteilung, die von vorherein bestimmte Verständigungsbedingungen voraussetzt" (Forget, p. 343). It is interesting to note here what he says in connection with the conditions of irony: "Es wird ein tragendes Einverständnis vorausgezetzt, wo immer Scherz oder Ironie möglich sein soll” (Forget, p. 348).
} 
At the end of the conversation, $\mathrm{K}$ has apparently been convinced and the dialogue seems to end in harmonious agreement [my emphasis]. ${ }^{28}$ The agreement is reached because $\mathrm{K}$, at first confused, has now as $\mathrm{C}$ puts it, been "put into possession of all that is needed to a process of understand (him)." Persuasion is linked to a process of understanding and what is "understood" is that the increased formalisation of consciousness, as in a machine, far from destroying aesthetic effect, enhances it; consciousness's loss is aesthetic gain.

It can probably be seen that Hermeneutics' so utterly valued agreement in the dialogical process of meaning creation and reaching of understanding also appears here, but from a different aspect. Here, the only possibility of reaching the desired understanding is to enframe consciousness within the boundaries of formalised knowledge, and make its working similar to that of a machine. This machine-like consciousness is supposed to be capable of concluding on an agreement in understanding, without the creative, conscious interpretative dialogue, and render the repeatability of itself possible.

All this is very threatening for Gadamer's concept of understanding, especially for the understanding a literary art-work renders. Yet, he attempts to tame knowledge or understanding, received by formalisation, by thrusting it into the category of scientific communication, thus ridding his higher order of literary works from the burden of formalisation, which thus proves to be only the concern of scientific communication. The question posed by de Man, however, cannot be made redundant: What if the aesthetic effect is or can be due to formalisation? How would it be possible then to differentiate between scientific or literary communication? The systematic rigour by which Gadamer aims to disciose anything that undermines his theory is reminiscent of the struggles of Speech Act Theory to create ever renewed categories in order to keep its system on the conditions of fulfiling a speech act plausible and to designate the group of exception or marginal cases which fall outside its concern. All in all, Gadamer

\footnotetext{
${ }^{23}$ The faliacy of the notion of "harmonious agreenent" (rapport) is what Derrida criticises Gadamer for and which Gadamer does not accept, nevertheless, Gadamer's reasoning against viewing his notion of understanding this way is not fully satisfactory: "The fact that a poetic text can so touch someone that one ends up 'entering' into and recognising oneself in it, assumes neither harmonious agreement nor self-confirmation," since it is repeating the contradictory double of recognising oneself without seli-confirmation. (Gadame:. "Reply to Jacques Derrida," p. 57).

29) Paul de Man. "Aesthetic Formalization: Kleist's Uber das Marionettentheater." The Rhetoric of Romanticism, p. 69.
} 
accepts a mode of understanding which is formalised and bound to reiteration, only this mode is excluded altogether when he turns to literary texts. Yet, the acknowledgement of this mode shakes the borderlines of literary and non-literary understanding. In order to save the uniqueness of literary works within his logic, Gadamer is forced to elaborate on textual forms traditionally considered to fall within the realm of the "literary." These forms, according to Gadamer, are to be taken as exceptions, since with their oscillation they seriously threaten the possible "Erscheinung" of the work of art, thus the possibility of arriving at understanding.

Gadamer therefore differentiates a group of text types, which are in "opposition to textuality" in order to "throw into relief what it means for a text to fulfil its authentic being [Bestimmung] as text, and to do so in terms of textual forms" (37). These types are the followings: "antitexts" [Antitexte], "pseudotexts" [Pseudotexte] and "pretexts" [Pretexte]. The other reason for maintaining this group of text types is that Gadamer, in his clinging to the dialogical nature of understanding, seeks for the residue of speech [Rede] in every kind of textual form as its underlying basis. Therefore, whenever he faces a textual form or notion which dissolves or dissimulates the original communicative situation or basis up to the point of unmasterability (of the text or of meaning), he tries to disclose it from the order of the literary, that is, from the order of the self-presenting text which, in the final analysis, would be able to speak for itself. His interest lies in the "voice" of the text, so much so that, apart from a succinct comment on the materiality of the written page, he completely ignores the query this materiality involves. To cite Gadamer:

the dispensability of such punctuation aids, which were not to be found at all in many ancient cultures, confirms how understanding is, nevertheless possible solely through the fixed givenness of the text. The mere sequence of written symbols without punctuation represents communicative abstraction in an extreme form (37).

Therefore, no matter how the text is given (in what form or what mode), it is no more than the minutes of the "original communicative situation," irrespective of any material form whatsoever.

\footnotetext{
${ }^{30}$ For further reference see Donald G. Marshall. "Dialogue and Écriture." In: Dialogue and Deconstruction.
} 
For Gadamer the material aspect of the written text is so dangerous, because it threatens the "underlying nature" of the notion of the voiced text. The unmasterable nature of the written text can be so vast that it can overgrown any "unity of understanding" any "transformation into structure [Gebilde]" (49). It entails the threatening possibility that, contrary to what Gadamer wants to see in favour of the sounded, on the one hand, "the unity of understanding and reading is only accomplished in a reading that understands and at that moment leaves behind the linguistic appearance of the text" and on the other hand, that "something else speaks in the literary text that makes present the changing relationship of sound and meaning" (49). Thus, what in fact carries the ever changing relationship of a text is its material nature that resides in the written letter, which very surprisingly chimes with a rather Deconstructive claim. Unfortunately, Gadamer's striving after the sounded repeats the previously observed contradiction related to the "Zeichenbestand" of the text - the entity to which one should return when the text fails to speak for itself. Yet, the notion of "Zeichenbestand" shifts the attention to the transparently repressed material aspect of the text in Gadamer's ultimate claims.

The query of the "disfiguring nature" of the letter - which is one of the most frequent terms of Paul de Man - is closely related to the notion of irony. To be exact, it is impossible to separate the two notions in de Man's terminology. The notion of irony is so crucial for my analysis, because it is what Gadamer discloses from the higher order of the literary under the heading of "antitexts."

In his definition "antitexts" are "forms of discourse that oppose or resist textualization because in them the dominant factor is the situation of interactive speaking in which they take place" (37). Deprived of suggestive tone or gestures the text cannot show univocally that it is not to be taken seriously. In the case of irony there is more in need in order to be decipherable without going astray: it "presupposes a common set of cultural understandings [gemeinsame Vorverständigung]" (37). ${ }^{31}$ Of course Gadamer operates with a common traditional sense of irony presupposing that in order to be able to conceive irony for what it

${ }^{31}$ Gadamer notes that "in very early aristocratic society" irony "made a smooth transition into writing" because of the "reigning agreement" (37). I am not certain about what he calls early, but if one considers Swift's Gulliver's Travels, which was written in a culture in which one can assume a "reigning agreement," it is quite surprising that his work was so utterly misunderstood as to be taken as a children's book, instead of a highly ironical criticism of the political era among other topics. 
is, a "supporting mutual understanding [ein tragendes Einverständnis]" (38) is required.

The idea of "supporting mutual understanding" nonetheless recalls what he claims in connection with scientific communication: "definite conditions of understanding." ${ }^{32}$ Though it is more suggestive in the German original: "Verständigungsbedingungen vorausgesetzt - Einverständnis aussetzen," it is suggestive enough in the English translation as well. Both irony and scientific communication are based on the same condition, no matter how far they are from each other. What matters only is the importance of keeping them under control by the avoidance of any probable misunderstanding (not to mention the probability of disseminating their meaning). One might nevertheless pose the question on the nature of this "vorausgesetzt" understanding, whether it is

\footnotetext{
${ }^{32}$ For a further elaboration of the idea of "definite conditions of understanding" one can take a look at Culler's "Presuppositions and Intertextuality," where he views the notion of intertextuality from a somewhat similar perspective of what Gadamer claims to be the fallacious or "lower level" condition of understanding. According to Culler "in the act of writing or speaking he [the individual] inevitably postulates an intersubjective body of knowledge" (Jonathan Culler. The Pursuit of Signs: Semiotics, Literature, Deconstruction. Ithaca, New York: Cornell University Press, 1981 , p. 101), in other words, he postulates "general expectations, implicit and explicit knowledge which will make his discourse intelligible" (Culler, p. 101). Thus according to Culler the intelligibility of a given discussion relies on a prior body of discourse, and he claims that by observing this he has "posed the problem of intertextuality and asserted the intertextual nature of any construct" (Culler, p. 101). Culler considers intertextuality as an instance which primarily focuses on intelligibility or on meaning. This way, in Culler's notion of it, "intertextuality' leads us to consider prior texts as contributions to a code which makes possible the various effects of signification. Intertextuality thus becomes less a name for a work's relation to a particular prior text than a designation of its participation in the discursive space of a culture" (Culler, p. 101). These discursive practices are not to be conceived as quotations, but as always already present in a cultural field without traceable origin. Culler's this kind of perception on intertextuality puts into question the status of citations from prior texts in the body of a work similarly to that of Deconstruction and, as I see, to that of Gadamer, (though deconstruction excludes the focusing on meaning or on intelligibility). If intertextuality is an "endless series of anonymous codes and citations" (Culler, p. 111), then an actual citation has no such a crucial role, if it is at all recognisable. He claims that "theories of intertextuality set before us perspectives of unmasterable series, lost origins, endless horizons" so "in order to work with the concept we focus it - but that focusing to some degree, undermine the general concept of intertextuality in whose name we are working" (Culler, p. 111). The intertextuality of a text, in this view, is impossible to master, since there are always only limited approaches to it, either we take intertextuality from the aspect of accounting for how "text create presuppositions and hence pre-texts for themselves" or from the aspect of the "conventions which underlie that discursive activity or space" (Culler, p. 118).
} 
inscribed into the text, constituted in it or falls outside of its realm and thus outside of its communicative force-field.

The problem is that neither aspect is acceptable within Hermeneutics. First, there is no probable outside of the dialogical understanding of textuality, as I have already noted. Second, if irony is inscribed into the text, then it is impossible to get rid of its oscillating code. It is precisely why irony is so dangerous. Faced with nothing but the material text it is impossible to say whether it should be taken seriously or not. Its double code thrusts everything into doubts and its reader to desperation. ${ }^{33}$ It is no accident that Gadamer notes that "even the hypothesis that one is dealing with irony may be hard to defend....to interpret something as irony often is nothing but a gesture of despair on the part of the interpreter" (38). In case of non-understanding the communicative-dialogical process of interpretation freezes, thus the return to the text comes to a halt. The interpreter in its desperation fallaciously calls the text ironical with an act of superimposition, but then it is not that he recognises irony as irony, but he mistakenly calls his non-understanding irony. The problem from Gadamer's side probably lies in the presumption that there is in fact a possibility for a situation "when one is able to say the opposite of what one means and still be sure that what one means is understood" (37). For Gadamer this "clearly shows that one is operating in a functioning communicative situation [Verständigungssituation?' (37).

In contrast Paul de Man's staring point is quite the opposite of this. Whereas Hermeneutics is concerned with the meaning of the said or spoken word. Deconstruction considers meaning only as a superimposition over the text,

\footnotetext{
${ }^{33}$ The threatening power of irony that lies here is neither fully overcome by Donald G. Marshall's interpretation who claims that "antitextuality" should be conceived as the opposite of "dialogue and writing [...] dialectically intertwined and together set against 'idle talk'" (Marshall, p. 209). According to him "antitexts" are forms of language which are "reduced either to empty talk that simply clings to a momentary social contact or to an unambiguous vehicle of information" (Marshall, p. 209). Thus writing or the written text shows its probably higher rank by not being temporal or momentary, but eternal or at least lasting and at the same time capable of changing its informative function or "meaningful expression" what the ineluctable intertwining of dialogue and writing renders to it. Thus Marshall considers it proven that Derrida is "ausdekonstriert" (outdeconstructed) by Gadamer since Gadamer's notion of writing includes both the deconstructive notion of écriture and the hermeneutical notion of lived dialogue the always differing "interplay of aporia and euporia" (Marshall, p. 209) and "the temporality of all insights" (Marshall, p. 209). This way it would be plausible to conceive writing as the vehicle to preserve the spoken word of dialogue without its ultimate fixation or without the separation of its materiality.
} 
that is, a superimposition over the letters of which the text is built up.. Why Gadamer tries to exclude irony from textuality is precisely why de Man builds his theory on it. Both authors are preoccupied with the dangers of irony in the possibility of understanding, therefore the two theories can be juxtaposed by the notion of irony, but as each other's inverse.

\section{IRONY IN THE PROCESS OF UNDERSTANDING}

De Man assumes that it is impossible to decide whether the text one is facing is ironical or not (still taking irony in its traditional Aristotelian sense), that is, whether or not it is to be taken seriously. Since there are no definite indicators or signals of what ironical is supposed to be, if "pursued to the end, an ironic temper can dissolve everything, in an infinite chain of solvents. It is not irony but the desire to understand irony that brings such a chain to stop." ${ }^{34}$ But de Man does not stop at this point, he puts into question whether anything like understanding can happen at all. His claim is fairly radical in comparison with that of 'Hermeneutics,' since he uncoils any probable notion of the event of understanding rendered in dialogue, or any possibility of true understanding in dialogue: He assumes that

if irony is of understanding, nc understanding of irony will ever be able to control irony and to stcp it $[\ldots]$ and if this is indeed the case that what is at stake in irony is the possibility of understanding, the possibility of reading, the readability of texts, the possibility of deciding on a meaning or on a multiple set of meanings or on a controlled polysemy of meanings, then we could see that irony is very dangerous. ${ }^{35}$

De Man in fact is trying to prove this assumption by conceiving irony in a curious way. What makes things even more complicated is, that there are different names he uses in more or less the same sense as he uses irony: they are, for instance, "the disfiguring power of the letter," "zero" or "hypogram." The impossibility of understanding is primarily due to the incompatible double code irony works with. "These two codes" he says "are radically incompatible with each other. They interrupt, they disrupt, each other in such a fundamental way

\footnotetext{
34 Paul de Man. "The Concept of Irony." Aesthetic ldeologies. Minneapolis: University of Minnesota Press, 1997, p. 166.

${ }^{35}$ De Man. "The Concept of Irony," p. 167.
} 
that this very possibility of disruption represents a threat to all assumption one has about what a text should be." ${ }^{36}$ In "The Concept of Irony," de Man actually, provides a definition of irony: "irony is the permanent parabasis of the allegory of tropes," ${ }^{37}$ and claims that "irony is precisely what makes it impossible ever to achieve a theory of narrative that would be consistent" since "it will be interrupted, always be disrupted, always be undone by the ironic dimension which it will necessary contain." 38

This disruptive parabasis is present at all points of the text and can be at work at any point, and seemingly without the realisation of the reader. The instance of irony seems to be more threatening than Gadamer actually shows it to be, since seen from this perspective, it works as a machine: it is "an implacable determination and a total arbitrariness... which inhabits the words on the level of the play of the signifier, which undoes any narrative consistency of lines." 39 The disruptive force of irony breaks up the illusion of the fiction which, to my mind, in hermeneutical terms can be seen as the unity of "Gebilde [shaped form, structure]."

Irony should also be conceived as the disruptive power of the letter, which in de Man's terminology culminates in the concept of "materiality." According to de Man the materiality of the letter explodes the seeming stability of the sentence and causes a slippage, which in turn undoes it and thus we lose control over its meaning:

The disjunction between grammar and meaning, Wort und Satz, is the materiality of the letter, the independence, or the way in which the letter can disrupt the ostensibly stable meaning of a sentence and introduce in it a slippage by means of which that meaning disappears, evanesces, and by means of which all control over that meaning is lost. ${ }^{40}$

In this sense irony is very much like "play on words [Wortspiel]," which Gadamer also wants to exclude from the literary, since as he says, the "play on words shatters the unity of discourse and demands to be understood in a higher relation of reflective meanings" (45).

\footnotetext{
${ }^{36}$ De Man. "The Concept of Irony," p. 169.

${ }^{37}$ De Man. "The Concept of Irony," p. 179.

${ }^{38}$ De Man. "The Concept of Irony," p. 179.

${ }^{39}$ De Man. "The Concept of Irony," p. 181.

${ }^{40}$ Paul de Man. "The Task of the Translator." Resistance to Theory. Minneapolis: The University of Minnesota Press, 1986, p. 89.
} 
Before this discussion becomes far too theoretical and abstract let us see what this radical conception on materiality means from the aspect of textual exegesis. The materiality of the letter is what one is faced with, which is "a first text in that it is nothing but text, nothing but a textual event, inexplicable in the punctuality as it is there." These lines call attention to de Man's analysis of Baudelaire's two sonnets: "Correspondances" and "Obsession." In de Man's study the textual event is "Correspondances" which is to be conceived similarly to what de Man writes about "authentic language" it is a "mere semiotic entity, open to radical arbitrariness of any sign system and as such capable of circulation, but which as such is profoundly unreliable." ${ }^{43}$

This is what Schlegel calls the origin of all poetry in "Rede über die Mythologie," which, according to him, is nothing but "error, madness and simpleminded stupidity" or "the original chaos of human nature." Baudelaire's "Correspondances" is an instance of this kind of poetic language. Despite having indulged into reading this sonnet, it is still not feasible to reach anything like Gadamer's "Gebilde" in the interpretative process. There is no place for anything else, but to create another sonnet as its reading, one like "Obsession." The problem nevertheless is that reading does not takes one closer to the understanding of the sonnet read, but creates another one with an act of superimposing meaning over the textual event of the previous text. In Gasche's view "Correspondances" - that is, the textual event which is to be interpreted - is an "infratext [...] the matricial senseless text, the hypogram to which all reading, as understanding, must respond - 'Obsession' being a case in point - reading can add only deception and error. [...] The subject is lured into producing an illuminating interpretation of the infratext that is in truth nothing but a fallacious addition" (emphasis mine). ${ }^{44}$ Hypogram condenses both: the material letter of the texts, their chaotic, arbitrary senseless nature, which by its circulation capable of disseminating meaning up to its uncontrollability and a figure superimposed over that inscription, whose existence, whose here and now is "undeniable as well as totally blank." ${ }^{45}$ It is impossible to conceive a moment when the written sign is devoid of its meanings; as Chase notes: "Like the 'moment' in which the position

${ }^{41}$ Rodolph Gasche. "Adding Oddities." The Wild Card of Reading. Cambridge: Cambridge University Press, 1998, p. 227.

${ }^{42}$ See Paul de Man. "Trope and Anthropomorphism in Lyric." The Rbetoric of Romanticism.

${ }^{43}$ Paul de Man. "The Concept of Irony," p. 181.

${ }^{44}$ Gasche, p. 228.

${ }^{45}$ Paul de Man. "Hypogram and Inscription." Diacritics Vol. 11 (1981), p. 28. 
of the sign occur as independent of the position of other signs, the text's materiality cannot be isolated as such or as origin, although it is the condition of possibility of any text." ${ }^{36}$

The idea of the machine-like working of the text results from de Man's notion of the materiality of the letter. The "smallest" constituent of writing is the letter - conceived in a pseudo-formalist or structuralist way - when one is to trace back how words and sentences build up the edifice of writing and that of the text. This idea leads de Man to attribute a curious power to the letter, which would work on its own terms, without the reading mind. Nevertheless, I detect some oscillation in his theory that can be grasped in his notion of prosopopeia. This figure states both: on the one hand, the preliminary attribution of meaning to the text in its materiality, which ultimately brings understanding and signification forth; and, on the other hand, the trope-bound, fallacious nature of any writing or language whatsoever. Without the presumption of the possibility of reading the text into meaning, the workings of prosopopeia cannot start off. But once it has started the fallacy in not to be avoided. The power of letter on its own terms can be maintained only in its relation to a reading mind, which is not in the position to control this power, but which, nonetheless, unconsciously contributes to its workings.

Writing according to de Man thus is what "devour[s] itself as the animal is said to devour sensory things in the knowledge that it is false and misleading. Writing is what makes one forget speech." ${ }^{47}$ But speech is not less a negativity than writing, on the contrary: "writing unlike speech and cognition, is what takes us back to this [Hegel's ever forgetting] ever recurring natural consciousness." ${ }^{48}$ In contrast the phenomenality of speech as voice is made into meaning, but this meaning can never correspond with either the experience one meant to communicate or with the meaning of the written text, since there is no such thing. It is always the disruptive and dissimulative as well as disseminative power of letters that are transformed into tropes which, in turn, are equally dissimulative. Whenever a meaning is superimposed on a set of words or letters the nominative process is set off. To put it somewhat differently, from the moment of granting names to things (which is entailed by a tropological act:

\footnotetext{
${ }^{46}$ Cynthia Chase. "Giving Face to the Name." Decomposing Figures. Baltimore and London: The John Hopkins University Press, 1986, p. 105.

${ }^{47}$ Paul de Man. "Hypogram and Inscription," p. 28.

${ }^{48}$ Paul de Man. "Hypogram and Inscription," p. 28.
} 
catachresis), we grant them properties as well, but these properties are created linguistically and are not a priori givens of things thus named.

In de Man's notion of reading or interpreting - and thus understanding can happen only intertextually, that is, through a hypertext ${ }^{49}$ (this concept in Genette's terminology coins the case when the entire field of the text, that is, the hypotext, is covered by the other text, the hypertext, written over it). The hypotext is the text read, which requires a reading in order to be conceived as text. Although Genette notes that the hypertext is not a commentary, it is very difficult to conceive any text covering entirely another not to be a commentary, unless it is an ironical superimposition rendering an endless oscillation between the two texts.

\section{THE INHUMAN ASPECT OF LANGUAGE? DE MAN AND GADAMER CONTRASTED}

At this point de Man's notion of interpretation is not much different from Gadamer's: both conceive the text as an intermediary product, that needs to be read for its realisation. The difference lies in the written status of the text in the two theories. According to Gadamer the literary text

overcomes not just the abstractness of being written in such a way that the text becomes readable, that is to say, intelligible in its meaning. Rather a literary text possesses its own status. Its linguistic presence as text is such as to demand repetition of the words in the original power of their sound - not in such a way as to reach back to some original speaking of them, however, but rather looking forward a new, ideal speaking (44).

Therefore the text as written form is only an abstraction, but its realisation happens through its reading into intelligibility, into meaning. Gadamer operates along or with the meaning of the text, which, in the final analysis turns out to be the Gebilde of the literary text. The Mit-rede as the interpretation of the text helps the text to present what it is. Although it presents itself always differently in the actual realisation of the reader, the understanding of the text - even if for an inconceivable moment - still turns into the unity of structure.

49 Gerard Genette. "Five Types of Transtextuality, among which Hypertextuality." Palimpsests: Literature in the Second Degree. University of Nebraska Press, 1997, pp. 1-7. 
De Man, on the other hand, claims that the only stable thing about a text is its material existence as a bundle of senseless letters. Although reading as interpretation is unavoidable, it does not lead to anything like its "real meaning" or to a Gebilde-like understanding. As Gasche says: "One text being given, the other must be present, at least in some fashion. [...] There are always two texts, one needing the other to be read and understood. The reader of a text is thus another text, its specular and inverse other." ${ }^{50}$ The compel to read thus cannot result in the understanding of the first text, no mater whether it is taken in Gadamer's sense as the "true" understanding reached by interpretation of the "first text" which covers that text entirely.

Yet, reading is impossible to get rid of, it is present in a double way, and both ways its function is that of interpretation, which results only in a fallacious superimposition. On the one hand, in its epistemological sense, reading can be conceived as the reading of things, (nature, culture or feelings etc.), but in this reading one (Man) cannot get closer to the "true" knowledge of these things as they are; s/he can only supply an interpretation of things according to what they seems to be. Since it happens by the means of language this interpretation cannot even be brought to an end, can never reach a stage when one with full assurance can claim to have been able to reach a final stage of the process. What language is capable of is the catachretic positing of things, which is capable of cxtreme proliferation. On the other hand, in its exegetic sense reading is to be considered as the event when, having faced an actually written text, it is to be pictured as the superimposition of meaning over a hypogram or hypotext.

The actual understanding of the text, nonetheless, is not categorically denied by de Man. Rather, what he denies is the fact that this understanding can by all means correspond to what the text is. There is understanding, yet what we believe to be our understanding is nothing "like a sudden instant of understanding ...in which the unity of the whole formulation is illuminated" (48), but the superimposition (and as such ideological) of what we thought to be understanding. The impossibility of bringing the interpretative process to a halt lies exactly in this, since at the moment one believes to come to an understanding the system is stopped (it is transformed into a structure), but that structure compels its own reading automatically, thus rendering ever newer texts to be read.

Gadamer, in contrast, sees the interpretative process as the meaning of the text, which, similarly to how it is in de Man's theory, covers the text entirely. In

${ }^{50}$ Gasche, p. 226. 
both cases the first text has an intertextual relation to its interpretation in Genette's sense of the term hypotext. The difference is that in Gadamer's view the two texts - as the text and its interpretation - merges in the Gebilde and calls forth the "whiling" [Verweilen] at the text, a presence "into which all mediatory discourse must enter" (49), that is, into the "self-presentation of the poetic word itself" (47). In contrast, there is no such a thing as this kind of merging of the two texts, no such thing as the "unity of the structure" in de Man's view, but the ever mistaken ideological superimposition of meaning as understanding.

Whereas Gadamer conceives the possibility of understanding in the possible dialogical situation and, in the final analysis, in the anthropological character of meaning creation, de Man puts the query into a completely different light. He does not deny that different aspects in viewing the world can be achieved or that understanding is altogether impossible. Yet, on the one hand, what he considers "true undesstanding" as only a possibility of reiterating previously set structures: it is their familiarity rather than their understood meaning which results in conceiving their reference. On the other hand, the possibility of reference is not totally dismissed by de Man: it is only that this reference is univocally determined by the text or immanent in the text what is dismissed. Due to the non-determinable system of figuration, which is at work on the textual inscription of semantic determinants, it is impossible to foresee what meaning the cext will generate. The performative act of creating the text, for instance, as inscription, is undeniable but what tropological system language engenders is impossible to foretell. The presumed understanding created in the reading process is only the retrospective superimposition of meaning granted to the text and, as such, it is ideological.

This theory pushes the possibility of understanding to its margins: how can it really be certain that one actually understands. The suspicion arises that if de Man is accually right then either the system is over-formalised in order to be understood or one can only reach ephemeral moments of personal insights, which by definition are fallacious. But Gadamer's query is not much different: it revolves around the same problem, since if Gadamer says understanding is always understanding-differently then how can this understanding be communicated?

In de Mar's view the system of signs and language is cverdetermined up to a point of despair since "it cannot be determined whether it [significance] is random or determined." At this point his claim is irreconcilable with that of

${ }^{51}$ Paul de Man. "Hypogram and Inscription," p. 29. 
Gadamer's, since it is not the "true understanding" or "Erscheinung" of the text which is present in the dialogical situation of understanding as understandingdifferently, but exactly the oscillation between those two things that constitute the Gebilde Gadamer talks of: the oscillating undecidability in favour of the one over the other.

Their different approaches to the written text is probably due to the inheritance of Platonic idea of writing (which even appears in Gadamer's work). There are two types of writing in this sense: the one which is written into the soul and the other that is written on the paper or papirus or inscribed onto whatever material. Plato refers to the former as: "The sort [of writing] that goes together with knowledge, and is written in the soul of the learner, that can defend itself, and knows to whom it should speak and to whom it should say nothing." ${ }^{52}$ The latter in Plato's wording is as follows:

And once a thing is put in writing, the composition, whatever it may be, drifts all over the place, getting into the hands not only of those who understand it, but equally of those who have no business with it; it doesn't know how to address the right people, and not address the wrong. And when it is ill-treated and unfairly abused it always needs its parent to come to its help, being unable to defend or help itself. ${ }^{53}$

Gadamer's theory on writing, in fact, resembles Plato's first concept, since his interest lies in the force of writing which is "written into the soul" (42) has. This might lead us to the Hegelian Gedächtnis-Erinnerung problem as it is discussed by de Man in "Sign and Symbol in Hegel's Aesthetic," reinforcing the same dichotomy on the notion of texts so far discussed in connection with the two schools. Therefore I take the opportunity to contrast them from another approach.

There is a dichotomy between the inscription of meaningless list of names, which de Man considers writing to be and Erinnerung, that is, the writing written into the soul, which is capable of recollection, "the inner gathering and preserving of experience. ${ }^{54}$ De Man says that Erinnerung functions alongside the metaphorical working of interiorisation: Erinnerung is capable of the "understanding of aesthetic beauty as the external manifestation of an ideal content

\footnotetext{
${ }^{52}$ Plato. Phaidros. The Collected Dialogues of Plato. New Jersey: Princeton University Press, 1979, $276 a$, p. 521.

${ }_{53}$ Plato, 275d-e, p. 520.

${ }^{54}$ Paul de Man. "Sign and Symbol in Hegel's Aesthetics." Aesthetic Ideology, p. 101.
} 
which is itself an interiorised experience, the recollected emotion of a bygone perception." 55 This allows for the "sensory manifestation [sinnliches Scheinen] of art and literature." Nonetheless, the problem is, as de Man points out, that where the "sensory appearance take[s] place" - which is the definition of art "as the material inscription of names" for Hegel is the learning by rote of names, or of words considered as the writing down of name, and it can therefore not be separated from the notation, the inscription, or the writing down of these names. In order to remember one is forced to write down what one is likely to forget. The idea, in other words, makes its sensory appearance, in Hegel, as the material inscription of names." ${ }^{57}$ Thus when Gadamer talks about the literary text "written into the soul" (42) he renews this tradition that leads from Plato through Hegel to Gadamer and beyond. For him the text or the work of art which is written into the soul can speak for itself, can shine forth [Erscheinung] showing its meaning, just like Mörike's lamp, according to his analysis in "Text and Interpretation," can begin to shine by the power of the work of art.

De Man, however, sees this kind of shining as only a fallacious metaphorical recuperation built into or projected onto the material inscription of letters, which Plato derides so much, yet uses as a device for his philosophy to be possible. The same applies to Hegel's Gedächtnis, which, in the final analysis, turns out to be the constitutive part of the entire system. "Representation," de Man notes, in the Hegelian theory "is in fact merely an inscription or a system of notations." ${ }^{58}$

The question can be carried forth by examining de Man's (or for that matter also Derrida's and J. H. Miller's) considerations of shining (and its connected notions: light, sun, gold, value). Seen from De Man's perspective the lamp in Mörike's poem can only shine due to the prior figuration of the apostrophe that states it as something capable of action, that is, shining by its own force, as something which has existence derived from and by itself. The initial apostrophe of "you lamp" is what calls forth the final statement of its possible shining which grants the lamp the ability of shining without any outside source of energy on its own terms, by grounding itself in itself. As Gadamer claims it is the

\footnotetext{
${ }^{55}$ Paul de Man. "Sign and Symbol in Hegel's Aesthetics," p. 101.

${ }^{56}$ Paul de Man. "Sign and Symbol in Hegel's Aesthetics," p. 100.

57 Paul de Man. "Sign and Symbol in Hegel's Aesthetics," p. 102.

${ }^{58}$ Paul de Man. "Sign and Symbol in Hegel's Aesthetics," p. 103.
} 
ability of the work of art, since it is "something that has developed into its own pattern from within and perhaps to be grasped in further formations [Bildung]" (49).

But what if this shining is not the unconcealedness of the poems being, the alatheia or Vorschein [appearance or beauty]. It might not be the comiig into the light of its essence as the sensory appearance of the idea. For shining is not only a property of value and that of gold, but it is also a property of the sun. But what shines forth with the sun? What is possible to know about the sun apart from its double nature of illuminating and blinding. What content, what value can one be certain of? As the sun in "White Mythology,"59 "Autobiography as Defacement," "Shelley Disfigured," ${ }^{60}$ or in Miller's "Illustrations" ${ }^{161}$ - to mention a few examples - the sun and its light are only the result of the figurality of a figure, a superimposition of a prosopopeia or catachresis over an entity whose properties are completely unknown to us, an attribution, an unknown instance or entity given a set of properties by merely the catachretic naming of it.

De Man's notion of the intertextual relation of two texts seriously question the possibility of ever reaching Gadamer's idea of the "Gebilde" of the work of art. Yet, it is not at all certain that he is right. Although both theorists maintain the possibility of closing the interpretative process, their radical difference lies in their concept on the nature of understanding, which, I am afraid will never be reconcilable. Settling the debate between the two schools is an infeasible project, yet their views can open different horizons in approaching a work of art. But it should not be forgotten that, in the final analysis, there might be more similarities than differences in these views.

\footnotetext{
59 Jacques Derrida. "White Mythology." The Margins of Philosophy. Chicago: University of Chicago Press, 1982.

${ }^{60}$ Paul de Man. The Rhetoric of Romanticism.

${ }^{61}$ I. Hillis Miller. Illustrations. Cambridge, Massachusetis: Har aud University Press, 1992.
} 